\title{
Erratum to: The effect of non-steroidal anti-inflammatory drugs and Helicobacter pylori infection on the gastric mucosa in children with upper gastrointestinal bleeding
}

Samir Boukthir · Sonia M. Mazigh •

Nicolas Kalach · Olfa Bouyahya · Azza Sammoud

Published online: 4 December 2009

(C) Springer-Verlag 2009

Erratum to: Pediatr Surg Int

DOI 10.1007/s00383-009-2492-x

Unfortunately the author name Nicolas Kaach was rendered wrongly. The correct name is Nicolas Kalach.

Also, Nicolas Kalach is affiliated with the Department of Saint Vincent de Paul Hospital, Catholic University of Lille, France, not to Hôpital d'enfants, Lille, France

The online version of the original article can be found under doi: 10.1007/s00383-009-2492-x.

S. Boukthir $(\bowtie) \cdot$ S. M. Mazigh · O. Bouyahya · A. Sammoud

Hôpital d'enfants, Tunis, Tunisia

e-mail: aboukathir@yahoo.fr

N. Kalach

Department of Saint Vincent de Paul Hospital,

Catholic University of Lille, Lille, France 